\title{
Quantitative comparisons of the color of CuAs, CuSn, CuNi, and CuSb alloys
}

\author{
Marianne Mödlinger ${ }^{1}$, Maikel H. G. Kuijpers ${ }^{2}$, Dennis Braekmans ${ }^{3}$, Daniel Berger ${ }^{4}$ \\ ${ }^{1}$ IRAMAT-CRP2A - UMR 5060 CNRS - Université Bordeaux Montaigne, Maison de l'archéologie, \\ Esplanade des Antilles, 33607 Pessac, France; Tel. : 00393401388506 \\ marianne.modlinger@u-bordeaux-montaigne.fr \\ ORCID: 0000-0002-7813-7846 \\ 2 Faculty of Archaeology, Einsteinweg 2, 2333 CC, Leiden University, The Netherlands, \\ m.h.g.kuijpers@arch.leidenuniv.nl \\ ${ }^{3}$ Cranfield Forensic Institute, Cranfield University, Defence Academy of the United Kingdom, \\ Shrivenham SN6 8LA, United Kingdom; Materials Science and Engineering, Delft University of \\ Technology, Mekelweg 2, 2628 CD Delft, The Netherlands, dennis.braekmans@ cranfield.ac.uk \\ 4 Curt-Engelhorn-Zentrum Archäometrie GmbH, D6, 3, D-68159 Mannheim, Germany, \\ daniel.berger@cez-archaeometrie.de
}

\begin{abstract}
The colors of copper alloys are of particular interest in archaeology and can be characterized quantitatively and systematically. The CIELAB color system can determine different color parameters such as $a^{*}, b^{*}$, and $L^{*}$ by means of a spectrophotometer that describes the surface color. Additional information such as $\mathrm{C}^{*}$ and $\mathrm{h}$ values can be calculated from these parameters which allows one to build a set of color-composition diagrams that connects chromaticity and alloy composition. With such data it is possible to estimate the color of prehistoric metal artifacts with similar chemical composition. A better understanding of the association between metallurgical composition and color will aid the research of prehistoric metalwork because choices in production and use of metal were likely influenced by this particular quality of metal.
\end{abstract}

\section{Keywords}

Copper alloys - color measurements - CIELAB - prehistoric metal work

\section{Nomenclature}

a* red/green value. It ranges from -100 (green) over 0 (grey) to 100 (red).

b* yellow/blue value. It ranges from -100 (blue) over 0 (grey) to 100 (yellow).

C* chroma. It describes the colorfulness relative to a white reference that is similarly illuminated. It takes values from 0 (achromatic) to $100 \%$ (fully chromatic).

CIELAB color space adopted by the International Commission on Illumination (CIE)

Gs Gloss is measured in gloss units, which use the angle of measurement and the gloss value. ASTM D523 standard recommends a $60^{\circ}$ geometry for the evaluation of gloss. The higher the gloss unit, the darker the color appears.

$\mathrm{h}$ hue or hue-angle. Hue is besides colorfulness, chroma, saturation, lightness, and brightness, one of the main properties of a color. It describes the degree to which a color can be described as similar or different to the six hues in the RGB (Red Green Blue) system: red, orange, yellow, green, blue, violet. Colors with the same hue can be for instance distinguished by further specification of their lightness and/or colorfulness: vivid green, pale green, light green. It ranges from 0 to $360^{\circ}$.

L* lightness. The lightness defines a range from dark $(0 \%)$ to fully illuminated $(100 \%)$. Every original hue has the average lightness level of $50 \%$.

$\mathrm{Ra}$ surface roughness. Surface roughness in micrometer range influences the level of specular reflectance (SR). Standards for gloss measurement comprise measurements at a specular angle of $20^{\circ}, 45^{\circ}, 60^{\circ}, 75^{\circ}$, and $85^{\circ}$, depending on the material measured. 


\section{Introduction}

Recent developments in material culture studies - be it cognitive approaches (e.g. Renfrew 2004, Boivin 2004), material engagement theory (Malafouris 2004; 2013), or a focus on craft and skill (Kuijpers 2013; in press) - all place particular emphasis on the qualities of materials; sometimes also referred to as affordances (sensu Gibson 1979; Knappett 2004).

The color of specific alloys is one such affordance. Several scholars have long assumed the importance of color in metalworking (Chapman 2007; Jones and MacGregor 2002; Juleff and Bray 2007; Kienlin 2008; 2010; Lehoërff 2007; Merkl 2010; Ottaway 2001; Pearce 2007; Stevens 2008; Smith 1975). There are strong indications that color played a role in how metal was perceived, symbolized, and valued (Jones 2004; Hosler 1994, 1995; Villegas and Martinón-Torres 2012; Leusch et al. 2015). Moreover, color was likely one of the key indicators of ore selections (Radivojevic et al. 2010; Radivojevic 2015), and there is evidence that particular objects were made with particular compositions, likely because of color (Hansen 2013; Pearce 2007) (Figure 1). Furthermore, one of the ways prehistoric metalworkers would have been able to recognize the difference in composition of (recycled) metals was by the color of the cast (Kuijpers 2013). Historical sources leave little doubt that recognizing the distinct colors of different alloys was an important skill for metalworking, and many describe alloys in terms of color (Guettier 1872; Agricola 1950; 1955; Biringuccio 1990; Hiorns 1912). The idea that composition may be determined through color measurement is even relevant in modern metallurgy (Kim et al. 2006). Nonetheless, very few quantitative analyses have been carried out with regards to metal color qualities (but see: Chase 1994; Fang and McDonnell 2011; Berger 2012). Color is not taken as a starting point for technological analysis, but is only loosely drawn in to interpret archaeometallurgical findings (e.g. Kienlin 2008; 2010 passim; Villegas and MartinonTorres 2012). This may be partly due to the lack of analytical rigor when addressing a quality like

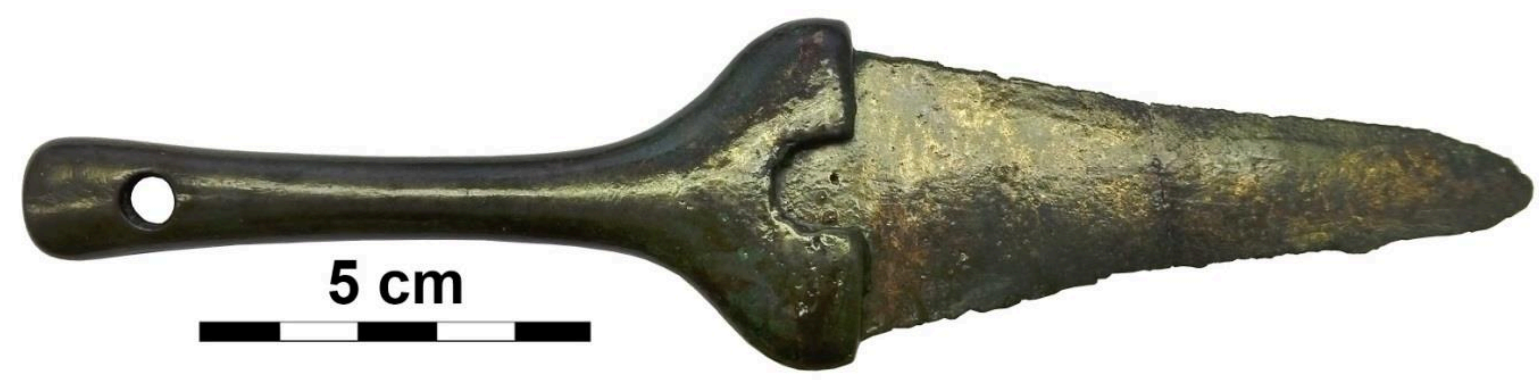

Figure 1 - Bronze Age dagger from Koban, Republic of North Ossetia-Alania, Russia. The color of the hilt was silverish while the blade had a warm, golden-like color. The hilt contains about 9.8 wt.\% arsenic and no tin, while the blade contains $10.1 \mathrm{wt}$ \% tin, and no arsenic. Today, the dagger is very much corroded, so the original colors of the metals are no longer visible (Photograph: M. Mödlinger, (C) Naturhistorisches Museum color.

Skills are fundamentally dependent on the senses, and operate at a level where the qualities and behavior of material are understood through sensory engagement with them (Budden and Sofaer 2009; Dobres 2000; Ingold 2011; Malafouris 2013; Kuijpers 2013). To operationalize such engagement using archaeological and archaeometallurgical data, the methodological approach of perceptive categories was developed (Kuijpers 2014). This methodology was conceived to challenge the gap between the material framework of the sciences and the social framework that contextualizes technology (Dobres 2010; Jones and MacGregor 2002; Killick 2004; Kuijpers 2013; Thornton 2009). The method works with the data provided by material sciences, but the thresholds with regard to the categorization and analysis of this data are based on the human senses, and thus on metalworking as a craft. In short, this method aims to organize the data into categories that are attuned to the aspects of the materials that are relevant to craftspeople. Lacking other more precise tools it is through the body that prehistoric metalworkers would have learned and categorized their materials. 
Color, taste, odor, and qualities of minerals which can be perceived by touch are most widely known because they are more easily recognized by the physical senses than qualities such as strength or weakness. A great many of these qualities are not known to everyone although those qualities which are learned through experience are widely known. (Agricola 1955, 5)

Both contemporary metalworkers and historical sources affirm that color was a key indicator of specific minerals and metals and their purity and this, therefore, relates to an (pre-scientific) understanding of compositional differences. It is on the basis of this that we assume that color is important for the metalworker since the raw material (i.e. the type of copper composition of the (scrap) metal) to a large extent defines how it can be worked, used, and/or alloyed. Hence, it is necessary to address this issue and examine to what extent specific elements that occur in prehistoric metal changes the color of pure copper. This approach will help strengthen the perception categories and provide better threshold conditions between categories. In turn, this should lead to the better understanding of why prehistoric metalworkers chose specific metal compositions for specific objects, how they developed and employed their skills, and how sensory engagement with an alloy led to knowledge about that material. Thus it is imperative to establish a set of measured color characteristics of different copper alloys. The data hitherto available from the literature (Chase 1994; Fang and McDonnell 2011; Berger 2012) does not provide a comprehensive basis for evaluation. On the one hand, alloys relevant to prehistory such as copper-nickel $(\mathrm{CuNi})$ and copper-antimony $(\mathrm{CuSb})$ were omitted completely. On the other, characterization of the color of copper-tin $(\mathrm{CuSn})$ and copperarsenic alloys (CuAs) was not always sufficient. Berger (2012) only provided reflectance curves, whereas Fang and McDonnell (2011) used only color values for their evaluation. It is thus the aim of our paper to combine both approaches by simultaneously extending the alloy basis.

From physics we know that color is caused through interaction of visible light with matter, of which absorption and reflection are the most influential. Opaque materials reflect light almost completely, whereas translucent or transparent ones are able to transmit light. For most materials, color can be observed due to internal absorption and scattering of light (Nassau 1998; Johnston-Feller 2001). Metals are extreme examples of opaque materials. They hardly absorb light but do reflect it almost completely at the metal-air interface. If metals (and other materials) are highly polished, they reflect light directionally, making them appear mirror-like or glossy. This type of reflection is called specular. Unpolished metals with rough surfaces, however, scatter light in many directions and reflect diffusely leading to a matte surface appearance. Both components add to the so called total reflectance, and are crucial in the appearance of metals since there is always a mixture of both.

In contrast to whitish or greyish appearing metals like silver, tin or iron, the specular reflection or gloss of colored metals such as copper, bronze, brass or gold is not uniform at all wavelengths in the visible light spectrum. The non-uniformity is due to light absorption in the uppermost layers of the metal crystalline structure and the transition of electrons into the conducting band of the metal atoms (Saeger and Rodies 1972; Lee 2005, 176). The specular component can thus be a carrier of color information. In order to describe the color appearance of colored metals properly a spectrometer is needed that determines both the specular and the diffuse reflection (Johnston-Feller 2001, 160).

In order to measure the color of different alloys, the metal surface has to be free of corrosion and equally prepared (i.e. the same levels of polishing or grinding applied). To enable a sufficient amount of different measurements (we used at 7-10 measurements per alloy), the surface of the alloy should have at least $5 \mathrm{~cm}^{2}$. Consequently, carrying out such analyses on archaeological finds is highly invasive and has to be avoided. In order to permit nevertheless the evaluation of the color of the metal of archaeological bronzes, we aimed to establish reference measurements on experimentally produced binary alloys similar to alloys commonly used in prehistory. In that way, one can, knowing also the alloy composition of the archaeological object, approximate its original color by comparing it with our measurements.

\section{Methodology}

Different series of copper-based alloys relevant to prehistory (CuAs, CuSn, CuNi, CuSb) were prepared in different laboratories by mixing electrolytic copper $(99.99 \mathrm{wt} \%)$ with pure alloying elements $(99.9$ wt.\%). Several samples were produced by a foundry with less pure copper (indicated 
with an $*$ in Table 1). The copper was heated until molten at $1110{ }^{\circ} \mathrm{C}$ (for arsenic) and $1200{ }^{\circ} \mathrm{C}$ (for antimony and tin) in graphite crucibles under reducing conditions. Weighed pieces or lumps of tin, antimony, and arsenic were added to the molten copper, however, nickel powder was heated with the copper. After the alloys were homogenized in the furnace by stirring with a carbon rod, and due to convection, the alloys were chill-cast into iron molds. While the samples made of $\mathrm{CuAs}, \mathrm{CuSn}$, and half of the CuNi samples were cold-rolled, the samples of $\mathrm{CuSb}$ and the other half of the $\mathrm{CuNi}$ samples were left as-cast.

All samples were embedded in epoxy resin and polished with SiC papers of up to 1200 grit, and diamond suspension paste down to $1 \mu \mathrm{m}$. It is important that the surface of the metal is consistent throughout free of scratches, cracks, or porosity, since the light can scatter due to these imperfections varying the light reflection properties (Yonehara et al. 2004). Measurements were carried out immediately after polishing to avoid surface alterations caused by oxidation. Freshly polished arsenical bronzes, for instance, quickly form oxides that appear as dull brown.

The chemical compositions of the metals were determined using either wavelength dispersive X-ray fluorescence spectrometry (WDXRF; Panalytical Axios Max) or an energy dispersive X-ray fluorescence spectrometer (EDXRF; Thermo Fisher Scientific ARL Quant'X). Since quantification was accomplished with reference alloys for both devices, the results, summarized in Table 1 for all alloys are comparable. It should be noted that the $\mathrm{CuSb}$ and some of the $\mathrm{CuNi}$ alloys contained between $0.3-0.5 \mathrm{wt} . \%$ aluminum and up to $0.5 \mathrm{wt} . \%$ in total combined silicon, chlorine, calcium, phosphorous, sulphur, iron, and potassium. The impurities derived from impurities in the copper, which was not electrolytically refined. However, such low concentrations of impurities are not influential in color measurement.

In our study, a MINOLTA CM-2600D hand-held spectrophotometer with an integration sphere was used. The device is equipped with a silicon photo diode array for detection and with three xenon light sources, each of which is employed for different illumination modes depending on what should be measured. In our case we used two light sources allowing the simultaneous determination of the diffuse and specular components by sequential illuminating the samples. Due to the integration sphere and the arrangement of the view port the samples were illuminated diffusely and directed towards the instrument at d:8 ${ }^{\circ}$ geometry (Johnston-Feller 2001; Germer et al. 2014). This relates to a viewing angle of $8^{\circ}(\theta)$ with respect to the normal (Figure 2). Although this geometry allows measurements with or without gloss, the specular reflection (SR) was included in our study (i.e. di:8 ${ }^{\circ}$ ) because of the above-mentioned reason. Prior to analysis the instrument was calibrated at an $8 \mathrm{~mm}$ aperture with two reference points (zero and white standard). The color parameters $\mathrm{L}^{*}$ (lightness), $\mathrm{a}^{*}$ (red/green value), and $\mathrm{b}^{*}$ (yellow/blue value) corresponding to the uniform color space CIELAB (Figure 3) were obtained from the instrument. Chroma ( $\left.C^{*}\right)$ and hue (h) could be calculated according to the following equations (the value of $\mathrm{h}$ is in degrees):

$\mathrm{C}^{*}=\left(\mathrm{a}^{*}\right)^{2}+\left(\mathrm{b}^{*}\right)^{2}$

$\mathrm{h}=\arctan \mathrm{b}^{*} \mathrm{a}^{*}$

In addition to these parameters, spectra were recorded for the total reflectance in the spectral range of 380-740 nm at intervals of $10 \mathrm{~nm}$. Seven to ten measurements were carried out for each sample, and the results averaged at each interval (Table 1). The color data $\mathrm{L}^{*}, \mathrm{a}^{*}$, and $\mathrm{b}^{*}$ were recorded and the two-dimensional color space, formed by $\mathrm{a}^{*}$ and $\mathrm{b}^{*}$, discussed below. 
The importance of uniformity in sample preparation, and the angle of the measurements are taken relative to the polishing lines, was first pointed out by Yonehara et al. (2004). Yonehara et al. (2004) studied the relationship between Ra (surface roughness), Gs (glosss), and the color of different alloys. Besides achromatic metals their research included tough pitch copper and copper alloys (brass C2801, and phosphor bronze C5191), which were polished with abrasive papers (unidirectional and multidirectional). The samples were measured in four directions relative to the polishing direction, and it was noted that $\mathrm{L}^{*}$ of all samples showed an inverse correlation with $\mathrm{Ra}$ and the SR that indicates Gs at $60^{\circ}$. Gs of all specimens increased exponentially as the arithmetical mean roughness Ra value decreased. Additionally, the blue hue of the surface color increased as Ra decreased.

Since total reflectance has been shown to be dependent on the degree of surface roughness (Ra), sample orientation, or the orientation of scratches (Yonehara et al. 2004), the spectral curves in this study have been normalized. Despite careful preparation, differences within each sample occurred, such as microporosity, orientation of scratches etc., that slightly affected the degree of diffuse reflectance between the alloys. Therefore, without normalization the effects of additives on the color characteristics of the studied copper alloys would not have been easily discerned from the spectral distribution curves. Normalization was achieved by moving (all points of) the curves along the y-axis until all graphs intersected the inflection point at $570 \mathrm{~nm}(580 \mathrm{~nm}$ for $\mathrm{CuSn})$, which was taken as the reference point. Prior studies on metal color with a static spectrophotometer indicated that all curves, except for $\mathrm{CuSn}$ alloys, run through the same reference point (cf. Berger 2012). Furthermore, spectral distribution curves were referred to the spectral curve of unalloyed copper that was not manipulated. This kind of manipulation does not impair the conclusions on the color characteristics of the alloys significantly since we only corrected the diffuse percentage of the total reflectance which is a measure of the lightness $\left(\mathrm{L}^{*}\right)$.

Table 1 - Alloy composition and color data (SR values) of the metal samples. The composition of the alloys is given in wt.\%. Alloys with * are as-cast and may contain up to 0.5 total wt.\% of Si, $\mathrm{Cl}, \mathrm{Ca}, \mathrm{P}, \mathrm{S}, \mathrm{Fe}$, and $\mathrm{K}$. All other alloys were made with electrolytic copper and were cold-rolled. The composition of the alloys with * were studied by WDXRF, and the chemical composition of all other alloys by EDXRF. The CIELAB coordinates are shown in Figures 5-9 and are the average of 7-10 spectra.

\begin{tabular}{|c|c|c|c|c|c|c|c|c|c|c|c|}
\hline alloy & As & $\mathbf{N i}$ & Sb & Sn & $\mathrm{Cu}$ & Al & $\mathbf{L}^{*}$ & $a^{*}$ & $\mathbf{b}^{*}$ & $C^{*}$ & $\mathbf{h}$ \\
\hline $\mathrm{Cu}$ & & & & & 100.0 & & 87.9 & 14.3 & 15.6 & 21.1 & 47.5 \\
\hline $\mathrm{CuAs} 2$ & 2.0 & & & & 98.0 & & 86.7 & 10.8 & 15.6 & 19.0 & 55.3 \\
\hline CuAs5 & 5.0 & & & & 95.0 & & 85.3 & 7.5 & 14.4 & 16.2 & 62.3 \\
\hline CuAs7 & 7.0 & & & & 93.0 & & 85.8 & 6.2 & 12.5 & 14.0 & 63.6 \\
\hline $\mathrm{CuAs} 15$ & 15.0 & & & & 91.0 & & 81.9 & 3.5 & 9.3 & 9.9 & 69.4 \\
\hline $\mathrm{CuNi0.5}$ & 0.5 & & & & 99.5 & & 87.9 & 13.5 & 15.0 & 20.2 & 47.9 \\
\hline CuNi1 & 1.0 & & & & 99.0 & & 87.4 & 13.0 & 14.8 & 19.6 & 48.7 \\
\hline $\mathrm{CuNi} 2$ & 2.0 & & & & 98.0 & & 87.1 & 11.8 & 14.4 & 18.6 & 50.7 \\
\hline CuNi3.4* & 3.4 & & & & 95.5 & 0.6 & 85.3 & 10.1 & 14.1 & 17.4 & 54.4 \\
\hline $\mathrm{CuNi} 4$ & 4.0 & & & & 96.0 & & 86.2 & 9.6 & 13.0 & 16.1 & 53.5 \\
\hline CuNi5.4* & 5.4 & & & & 93.2 & 0.9 & 86.2 & 8.4 & 11.9 & 14.5 & 54.8 \\
\hline CuNi6 & 6.0 & & & & 94.0 & & 86.1 & 7.8 & 12.0 & 14.3 & 56.8 \\
\hline CuNi6.3* & 6.3 & & & & 92.5 & 0.7 & 86.6 & 7.6 & 11.3 & 13.6 & 56.1 \\
\hline CuNi6.6* & 6.6 & & & & 92.3 & 0.6 & 86.2 & 7.3 & 11.3 & 13.4 & 57.0 \\
\hline CuNi7.9* & 7.9 & & & & 90.8 & 0.8 & 86.6 & 6.1 & 10.6 & 12.2 & 59.9 \\
\hline $\mathrm{Ni}$ & & 100.0 & & & & & 77.3 & 0.7 & 5.5 & 5.5 & 82.6 \\
\hline CuSb1.6* & & & 1.6 & & 97.5 & 0.4 & 85.5 & 14.4 & 16.7 & 22.0 & 49.1 \\
\hline CuSb3.3* & & & 3.3 & & 95.8 & 0.4 & 85.5 & 13.3 & 17.4 & 21.9 & 52.6 \\
\hline $\mathrm{CuSb} 3.9 *$ & & & 3.9 & & 95.2 & 0.4 & 86.4 & 11.5 & 16.9 & 20.4 & 55.8 \\
\hline $\mathrm{CuSb} 4.4^{*}$ & & & 4.4 & & 95.1 & & 85.6 & 12.5 & 17.1 & 21.2 & 53.8 \\
\hline CuSb6.1* & & & 6.1 & & 93.1 & 0.3 & 84.1 & 10.6 & 17.4 & 20.3 & 58.7 \\
\hline $\mathrm{CuSb} 7.3 *$ & & & 7.3 & & 92.0 & 0.3 & 86.5 & 9.4 & 15.8 & 18.4 & 59.3 \\
\hline $\mathrm{Sb}$ & & & 100.0 & & & & 88.6 & -0.8 & -0.5 & 0.9 & 31.8 \\
\hline $\mathrm{CuSn} 1$ & & & & 1.0 & 99.0 & & 85.9 & 14.7 & 16.7 & 22.2 & 48.7 \\
\hline $\mathrm{CuSn} 2$ & & & & 2.0 & 98.0 & & 86.0 & 13.7 & 16.2 & 21.2 & 49.8 \\
\hline $\mathrm{CuSn} 4$ & & & & 4.0 & 96.0 & & 87.4 & 11.8 & 19.0 & 22.4 & 58.1 \\
\hline
\end{tabular}




\begin{tabular}{lrrrrrrr} 
CuSn6 & 6.0 & 94.0 & 89.0 & 9.4 & 18.6 & 20.8 & 63.2 \\
CuSn7.3 & 7.3 & 92.7 & 88.7 & 8.0 & 18.8 & 20.5 & 66.9 \\
CuSn9.5 & 9.5 & 90.5 & 88.7 & 7.8 & 19.0 & 20.5 & 67.6 \\
CuSn11 & 11.0 & 89.0 & 88.7 & 5.9 & 20.7 & 21.6 & 74.1 \\
CuSn12.7 & 12.7 & 87.3 & 84.9 & 5.5 & 19.7 & 20.5 & 74.4 \\
CuSn16.3 & 16.3 & 83.7 & 86.7 & 5.2 & 16.9 & 17.7 & 73.0 \\
Sn & 100.0 & & 92.0 & -0.4 & 3.3 & 3.3 & 276.7 \\
\hline
\end{tabular}

Because different thermal or mechanical treatments can also lead to different CIELAB coordinates (Fang and McDonnell 2011), it is important that alloys are prepared the same way. This requirement applies to our metals except the CuNi alloys, which were prepared as-cast and coldrolled. Potential differences caused by differing treatments could be highlighted with this.

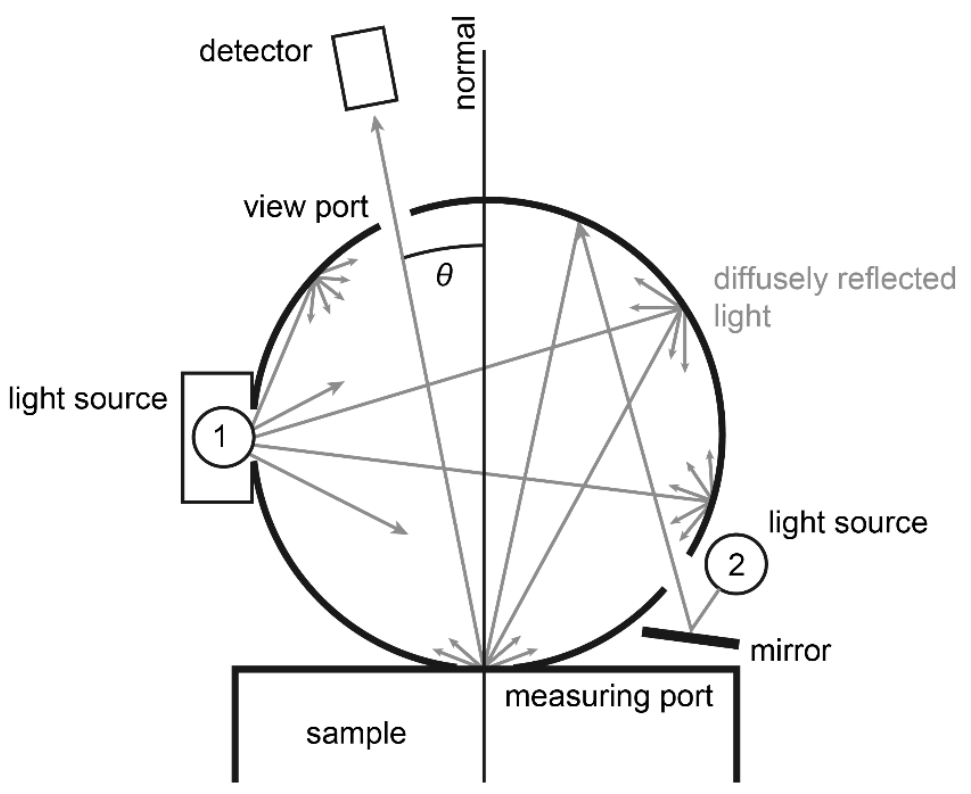

Figure 2 - Schematic drawing of the sample illumination during the color measurements with the MINOLTA CM-2600D spectrophotometer using an integration sphere. Due to the sequential application of two different light sources (1 and 2), quasi-simultaneous measurements of the diffuse and specular components of the reflectance are possible (drawing: after Konica Minolta 2014, E-116)

Within the uniform, three-dimensional space CIELAB, an index of lightness $\left(\mathrm{L}^{*}\right)$, and two color coordinates $\left(a^{*}, b^{*}\right)$ were defined. $L^{*}$ ranges from black $(0)$ to diffuse white $(100)$, $a^{*}$ takes positive values for magenta and negative values for the green (as the complementary color of magenta), whereas $b^{*}$ takes positive values for yellow and negative values for blue (as the complementary color of yellow) (Figure 3). 


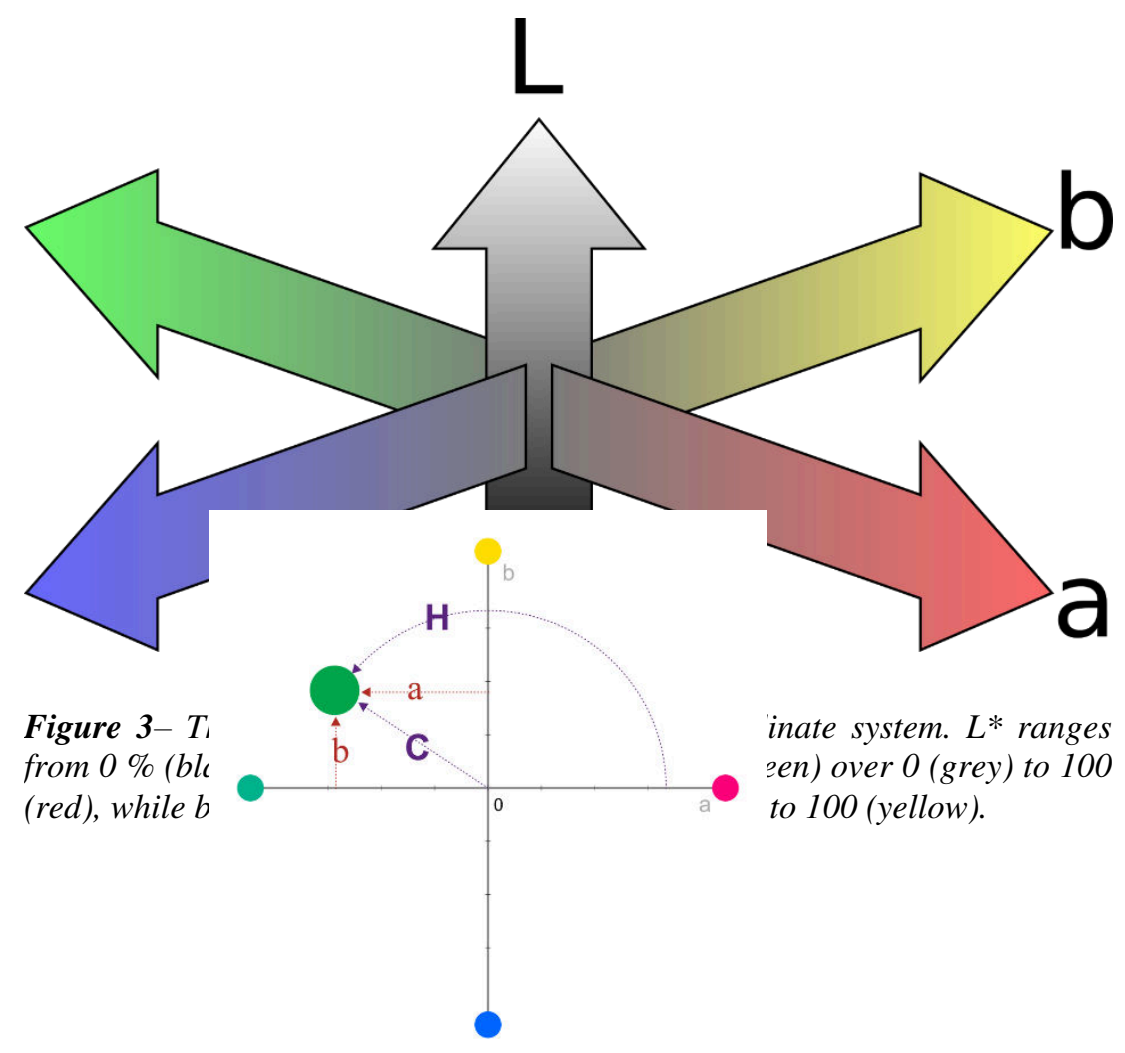

Figure 4 - Two-dimensional chromaticity diagram of the $L^{*} a^{*} b^{*}$ color space with a view to the $a^{*} b^{*}$ plane with constant $L^{*}$. $C^{*}$ and $h$ can also be included in diagram (drawing: D. Berger)

Figure 5 (left) depicts the $a^{*}$ and $b^{*}$ values of the pure copper, antimony, tin, and nickel. The color of pure arsenic was not studied since arsenic was only available as a powder, which was used to produce the CuAs alloys. Because the arsenic was in powder form, it was not possible to guarantee each sample was the same. Moreover, the arsenic was slightly discolored by oxidation.

\section{Results}

Metalloid arsenic is nearly indistinguishable from antimony in color. Its metallic luster quickly tarnishes to dark gray or black (Figure 5, left). As can be seen from Figure 5 (right), the reddish color of copper is caused by its high reflectance in the orange-red spectral range (600-700 nm), while tin, antimony, and nickel display an even reflectance throughout their entire visible light spectral range. Their reflectance characteristics are why these metals appear gray or silvery. One might think that the $a^{*}$ and $b^{*}$ values of these three elements, once alloyed with copper, group in a linear trend; however, this is not entirely true and will be discussed below.

\section{CuAs}


There is a drop in the $\mathrm{a}^{*}$ value of the CuAs alloy with an addition of 2 wt.\% arsenic to the copper (Figure 6a), which draws the alloy towards a greenish color. With increasing amount of arsenic, the $\mathrm{a}^{*}$ value decreases even further, but $b^{*}$ simultaneously decreases, drawing the color towards blue. The perceived result is a more white-grayish appearance of copper with increasing arsenic content. This trend can also be seen from the spectral distribution curves shown in Figure 7a. The curves are similar to unalloyed copper, but $\mathrm{CuAs}$ alloys show a continuous decrease in reflectance in the orange-red $(600-740 \mathrm{~nm})$, and an increasing reflectance in the blue-green spectral range $(380-550 \mathrm{~nm})$ with increasing arsenic content. CuAs 15 reflect light almost evenly throughout the spectrum, and with that it displays a similar spectral development as pure nickel (cf. Figure 6b) meaning a pronounced whitegrayish color. The low $a^{*}$ and $b^{*}$ values in Figure $6 a$ are an indicator for that, too. The color values for pure arsenic are simulated in that figure using the mean values of tin and antimony, and indicated only by the end of the polynomic line, hence no exact indication for arsenic is given (there are no published values for pure arsenic either). Simulation of the native arsenic was done due to health
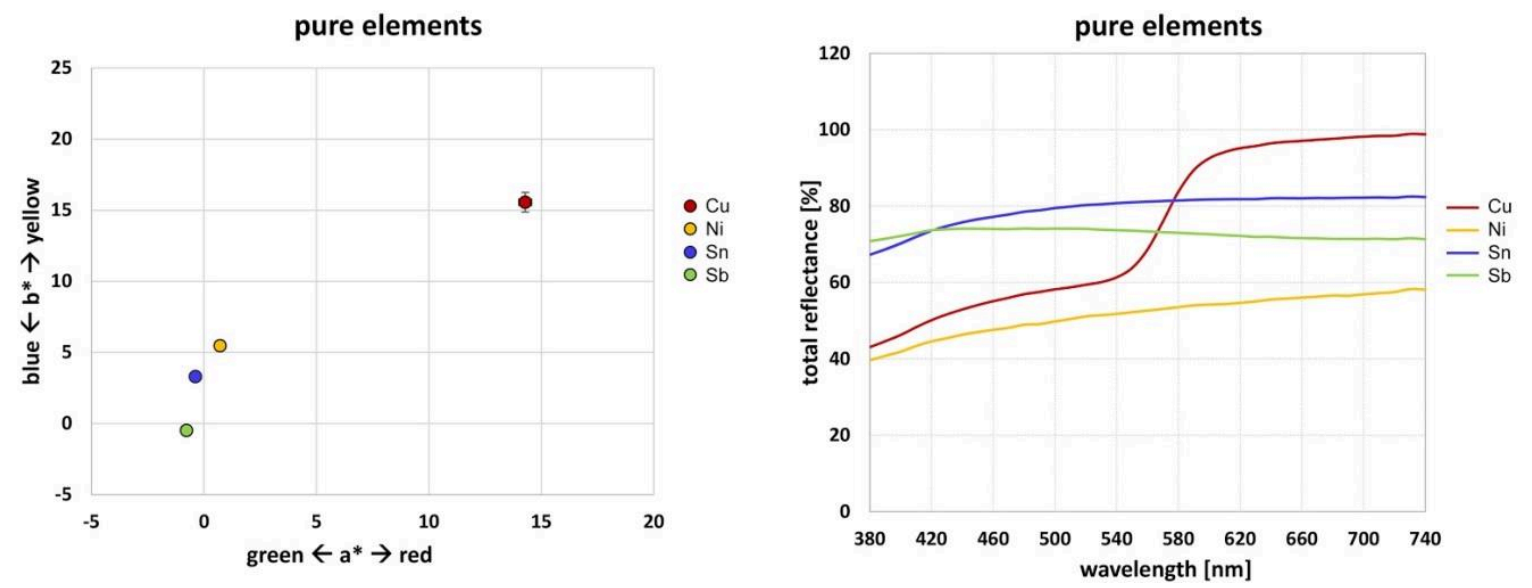

Figure 5 - CIELAB SR coordinates with error bars (Standard deviation: 2 $\sigma$ ) of samples polished with $1 \mu m$ diamond paste of selected pure elements: copper, nickel, tin, and antimony (left). Spectra of the same elements (mean value of 7-10 spectra) (right).

risks.

\section{CuNi}

In contrast to the CuAs alloys that show a polynomic trend with increasing arsenic content, the CIELAB coordinates of the CuNi alloys are arranged almost linearly from reddish copper to grayish appearing nickel (Figure 6b). The more nickel in the copper, the more the color is drawn towards green $\left(a^{*}\right)$ and blue $\left(b^{*}\right)$, which are seen as a graying of the metal (cf. Figure 3 ) Even though half of the samples were either cold-rolled or as-cast, there is no notable effect on the color which would have been recognizable in a systematic deviation of the differently treated metals. Moreover, impurities in the copper, as specified in Table 1, do not apparently affect the color characteristics.

The linear dependency is illustrated by the spectral distribution curves as well (Figure $7 \mathrm{~b}$ ). Again, reflectance in the orange-red spectral range is decreased, while reflectance in the blue-green spectral range rises continuously with increasing amounts of the alloying component. This leads to a more even reflectance and an increased graying in the $\mathrm{CuNi}$ alloys.

\section{CuSb}

Compared to the $\mathrm{CuNi}$ alloys, the reflectance of the $\mathrm{CuSb}$ alloys in the blue-green spectral range remains almost constant as reflectance in the orange-red spectral range decreases noticeably (Figure $7 \mathrm{c})$. Hence, graying of alloys with up to $7.3 \mathrm{wt} . \%$ antimony is not as pronounced as observed in $\mathrm{CuNi}$ and $\mathrm{CuAs}$ alloys with similar amounts of nickel and arsenic, respectively. There is a decrease in $\mathrm{a}^{*}$ towards greener values, and a slight increase in $b^{*}$ towards yellow with the addition of antimony (Figure $6 \mathrm{c}$ ). This trend continues until around 6-7 wt.\%, after which $\mathrm{b}^{*}$ finally drops drawing the color of the alloy towards blue as antimony content rises. 


\section{CuSn}

With the addition of up to $2 \mathrm{wt} . \%$ tin to the copper only small changes in the color characteristics of the $\mathrm{CuSn}$ alloys can be observed. Not until the tin content rises to $4 \mathrm{wt} . \%$ and more, the alloys become less red and a little bit more yellow indicated by gradually rising (and then almost stable) $\mathrm{b}^{*}$, and dropping $\mathrm{a}^{*}$ values (Figure 6d). Reflectance in the orange-red spectral range of these alloys decreases similarly compared to the other alloys, but at the same time reflectance between $500-580 \mathrm{~nm}$ for CuSn7.3 to CuSn16.3 increases explicitly accompanied by rising b* values (Figures $6 \mathrm{~d}$ and $7 \mathrm{~d}$ ). This behavior of $\mathrm{CuSn}$ is different than the other alloys, and since the change in reflectance in the blue range $(380-500 \mathrm{~nm})$ is not that high, CuSn alloys with up to ca. $16 \mathrm{wt} . \%$ tin are perceived as yellow (Fang and McDonnell 2011 note 15 wt.\% Sn). Yet, the dropping $b^{*}$ value for CuSn16.3 indicates that color becomes gradually more grayish in appearance when the tin content is further increased (Figure $6 d)$.
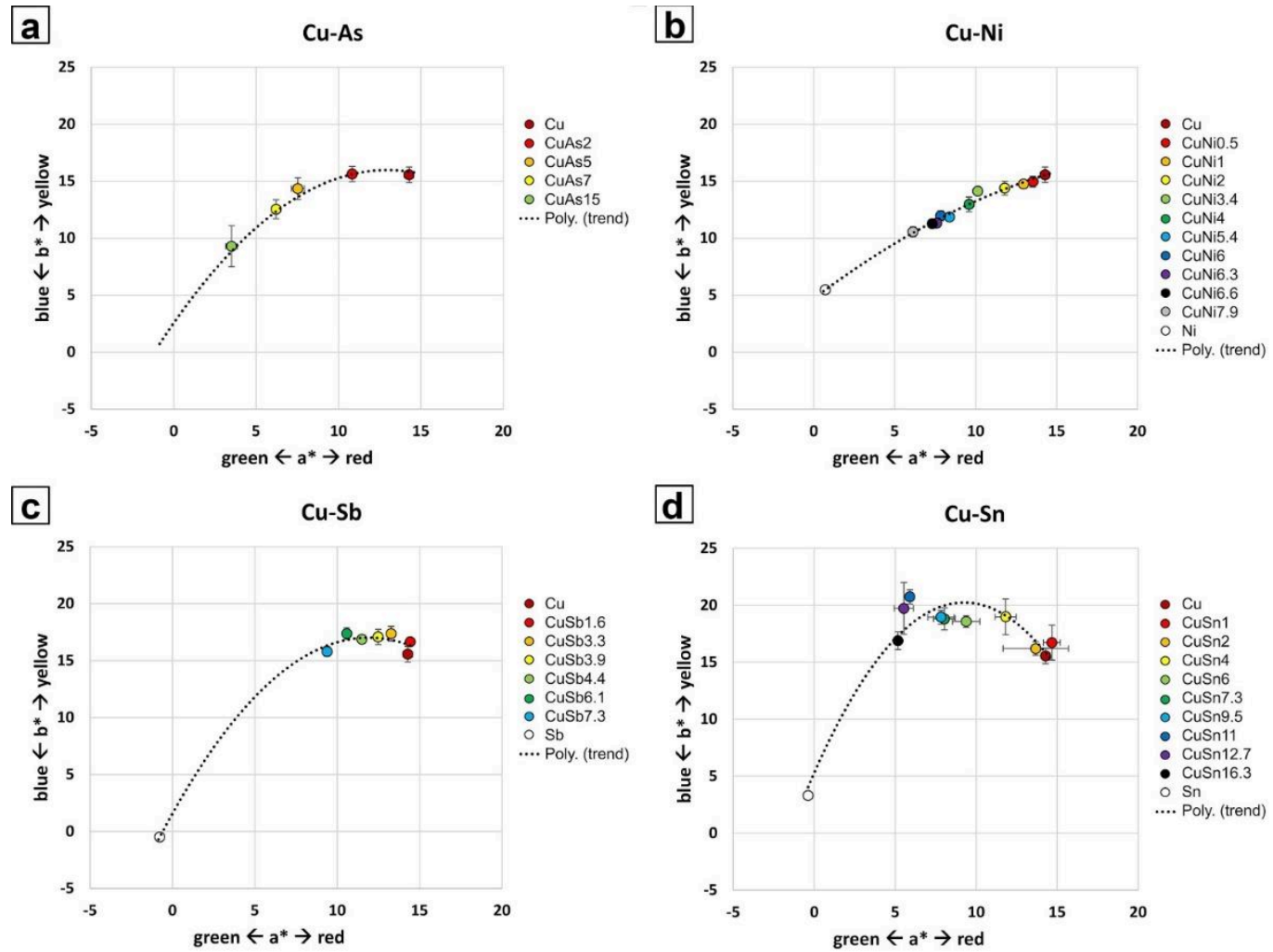

Figure 6-CIELAB coordinates (SR) with error bars (standard deviation: $2 \sigma$ ) of each copper alloy examined in this study. 

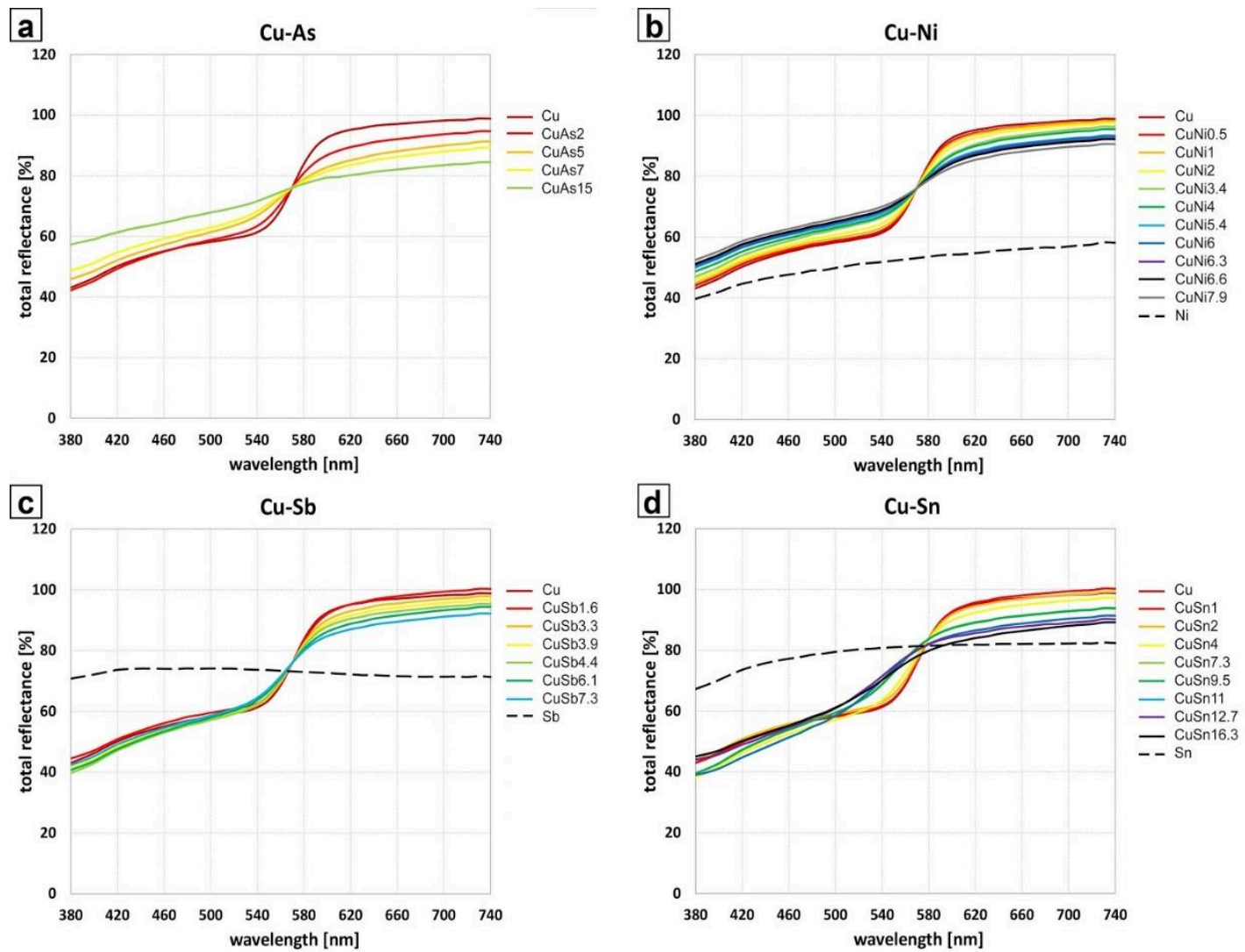

Figure 7 - Spectral distribution curves of the same alloys as shown in Figure 6 with wavelength vs. total reflectance. For each alloy 7-10 measurements were taken and averaged.

\section{Discussion}

When interpreting the color measurements it is important to keep in mind that differences in properties - in this case in the $\mathrm{L}^{*}, \mathrm{a}^{*}$, and $\mathrm{b}^{*}$ values - do not necessarily equal perceivable differences in color qualities. To move from the scientifically measured properties to archaeologically relevant use of these results, two additional questions need to be answered:

1) Are the effects recognizable?

2) Are they relevant for metalworking?

These question are at the core of the perceptive categories approach.

A comparison of the color behavior of the copper alloys studied is shown in Figure 8 and 9. With chroma $\left(\mathrm{C}^{*}\right)$ as a measure of the colorfulness Figure 9a provides a tool to evaluate the degree of coloration or discoloration with the amount of alloyed metal. It is seen by the dropping $\mathrm{C}^{*}$ values that the addition of nickel, at least up to $8 \mathrm{wt} . \%$, has a similarly strong impact on the initially coppery color as arsenic, in that the alloys become more achromatic or grayish. In contrast, additions of antimony and tin change the color to a much lesser degree when a similar amount of them are alloyed with copper. This is suggested by their almost stable and slightly dropping $C^{*}$ values. These differences are the reason why color changes of $\mathrm{CuAs}$ and $\mathrm{CuNi}$ alloys can already be perceived with as little as $2-3 \mathrm{wt} . \%$, while changes for $\mathrm{CuSn}$ and $\mathrm{CuSb}$ alloys are more difficult to notice. Only when concentrations of about 4 wt.\% or more are present a clear distinction is possible. Lower concentrations do have an effect on the redness of pure copper, too, but without directly comparing samples to each other the slight change in color (from red to salmon-red) of the samples containing some antimony or tin is hardly noticeable. From $4 \mathrm{wt} . \%$ and up tin bronzes become gradually more yellow achieving their warm, yellowish color around $9 \mathrm{wt} . \%$ tin (Figures 8 and $9 \mathrm{~b}$ ). This is indicated by highly rising values of hue (h) which is a measure of the tone of a color (Figure $9 \mathrm{~b}$ ). A maximum in yellowness for our alloys is reached between 11 and $13 \mathrm{wt} . \%$ tin, which can be seen by now almost stable $h$ values. Up to $13 \mathrm{wt}$.\% tin $\mathrm{C}^{*}$ is almost constant, too but after that it begins to drop suggesting 
that the CuSn alloys become grayer. Such a graying effect (or silvering because of gloss) is much more evident for the $\mathrm{CuAs}$ and $\mathrm{CuNi}$ alloys whose $\mathrm{C}^{*}$ values are lowered significantly with increasing content of alloy additive (Figure 9a). At the same time, $\mathrm{h}$ is changed to a lesser degree for these alloys than for bronzes with a similar amount of tin (Figure 9b-c). This shows that the tone of the red color is not changed as effectively. For CuSb alloys, $\mathrm{h}$ is affected to the same degree as CuNi alloys, but since $\mathrm{C}^{*}$ is only slightly reduced with increasing antimony content, graying of these alloys is less apparent.

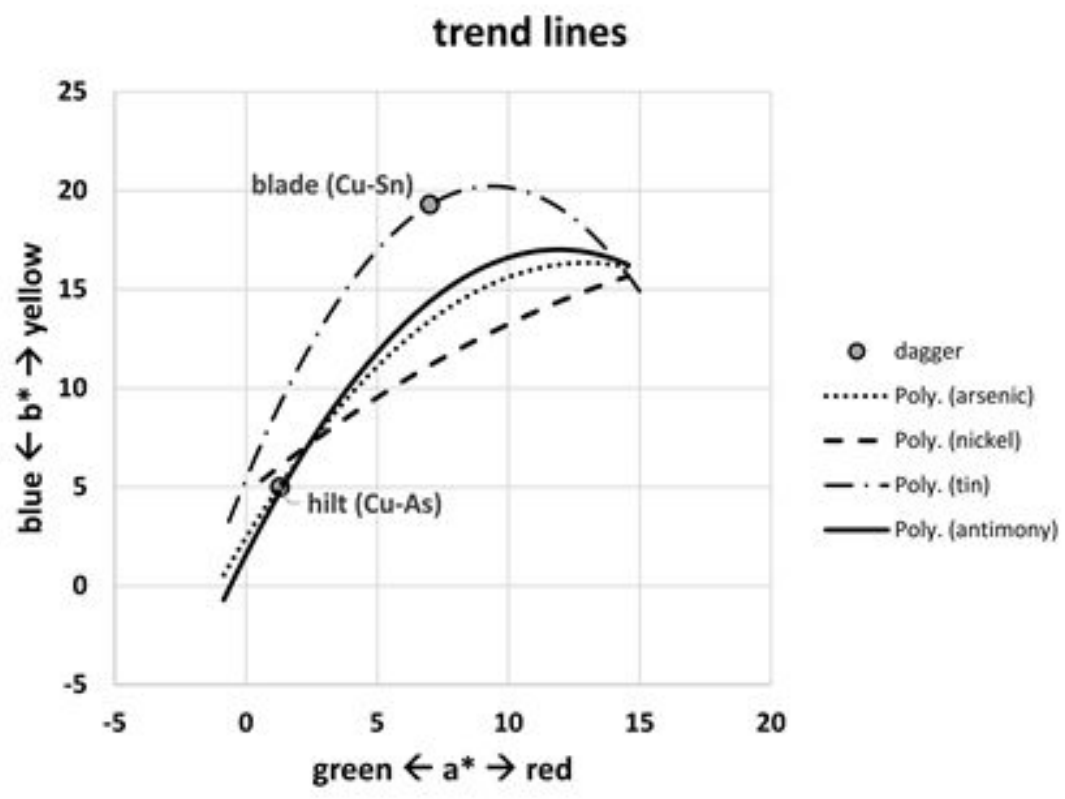

Figure 8 - Polynomic lines of the CIELAB coordinates for each alloy (see also Figure 6), including the estimated coordinates for the hilt and blade of the dagger (Figure 1) according to the alloy composition of both hilt and blade. 

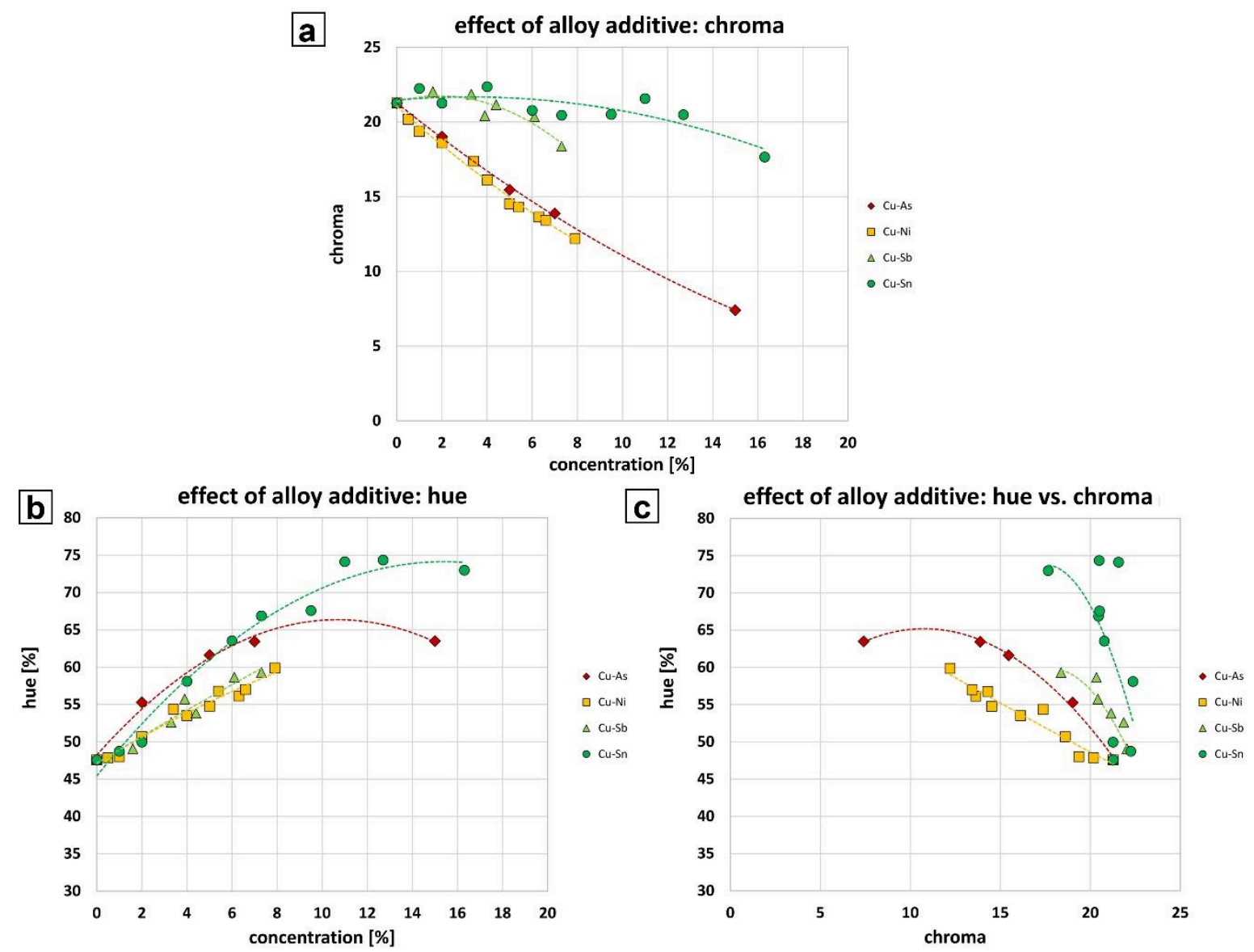

Figure 9 - The effect of different alloy additives on copper shown as the dependence of chroma (a) and hue (b) from the amount of alloying element given in wt.\%. In c) chroma vs. hue of the different alloys is shown. Chroma given in $\%$.

While the results given here irrefutably show the effect of alloying on color, they in themselves cannot tell us how they are perceived or relevant to metalworking. As for the first question, it is obvious that the main problem is that color is in the eye of the beholder: the perception of metal color is influenced by many factors such as light, surface roughness, patination and oxidation, chemical composition and manufacturing technology (segregation), only to name a few. To tackle this problem there are two possible approaches: first, one could make use of psychophysics, a field concerned with the relationship between perception and the physical world quantifying the acuity of our sensory modalities (Gescheider 1997); and second, one could compare and balance the scientific findings with the craft knowledge of experienced metalworkers written down in historical sources and/or contemporary craftspeople. The first approach could be used to set the threshold color differences that should be perceivable by the human eye. Essentially, this could be described as a quantitative phenomenology (Teghtsoonian 2001, 13903). The latter approach is also a potential avenue to find answers to the second question.

It is this second approach that led to the methodology of perceptive categories. The perceptive categories for metal types (Table 2) that Kuijpers (2014) proposed are a conjecture of the little available data on color measurement, historical sources, and contemporary metalworkers. These categories do not reflect emic categories but are an attempt to understand 'metallity' (Bray 2012; Untracht 1968, 5-6), by which is meant the manner in which metal behaves and can be perceptibly understood by craftspeople. This is why other qualities such as malleability, brittleness, casting quality, and even sound are also included. Here, we have tested one particular quality which is color, and the discussion that follows focuses only on this quality. 
Table 2 - Perceptive categories of different CuSn metal types as thought relevant and perceivable to metalworkers. These metal types are based on interviews with contemporary craftspeople, historical sources, and experimental archaeology (from Kuijpers 2014; in press).

\begin{tabular}{|l|l|l|}
\hline $\begin{array}{l}\text { Metal type (perceptive } \\
\text { category) }\end{array}$ & $\begin{array}{l}\text { Composition } \\
\text { (approximate) }\end{array}$ & Physical and mechanical qualities \\
\hline Type I - Red copper & $\begin{array}{l}1-5 \% \mathrm{Sn} \\
\text { or } \\
1-3 \% \text { of As, Ni, } \\
\mathrm{Sb}, \mathrm{Ag}\end{array}$ & $\begin{array}{l}\text { Red-pink to brownish-orange, or dull golden-brown. Soft and } \\
\text { easily workable. Suitable for objects that need a lot of } \\
\text { shaping. }\end{array}$ \\
\hline Type II - Orange copper & $\begin{array}{l}3-7 \% \mathrm{As}, \mathrm{Ni}, \mathrm{Sb}, \\
\mathrm{Ag}\end{array}$ & $\begin{array}{l}\text { Orange-brown-golden. Noticeable hue undertones: purple } \\
\text { (Sb), bluish (Ni), or pale silvery-white (As). Harder but also } \\
\text { more brittle metal. }\end{array}$ \\
\hline Type III - Yellow copper & $5-12 \% \mathrm{Sn}$ & $\begin{array}{l}\text { Orange-brown to yellow-golden. At 10\% when polished } \\
\text { distinctly golden ('typical' bronze color). Good casting } \\
\text { qualities. Rapid increase in hardness when hammered with } \\
\text { manageable brittleness. Predictable metal. }\end{array}$ \\
\hline Type IV - Gold copper & $12-20 \% \mathrm{Sn}$ & $\begin{array}{l}\text { Yellow-golden to pale yellow. From 17 \% onwards light } \\
\text { white-silvery. Very good casting qualities. Rapid increase in } \\
\text { hardness but very brittle. High risk of cracking. Predictable } \\
\text { but less forgiving. Well suited for objects that need to be } \\
\text { hard as-cast. Sonorous qualities. }\end{array}$ \\
\hline Type V - White copper & $\begin{array}{l}>7 \% \mathrm{As}, \mathrm{Ni}, \mathrm{Sb}, \\
\mathrm{Ag}\end{array}$ & $\begin{array}{l}\text { Distinctly blue-white to white-silver. Hard but also } \\
\text { exceedingly brittle; cracks quickly. Difficult casting } \\
\text { qualities. Unpredictable and demanding material. High risk } \\
\text { of cold- and hot-shorts. }\end{array}$ \\
\hline Type VI - Silver copper & $>20 \% \mathrm{Sn}$ & $\begin{array}{l}\text { Yellow-white to white-silver. Very good casting qualities. } \\
\text { Brittleness forbids cold-working. Very suitable for objects } \\
\text { such as bells and horns. Sonorous material. }\end{array}$ \\
\hline
\end{tabular}

The color measurements presented in this article largely support the proposed perceptive categories in terms of colors but add some important nuances. Metal types I, II, and IV (cf. Table 2) are categories in which arsenic, antimony, nickel, and silver are all taken together because prehistoric metals, especially in the Early Bronze Age, often contain all of these elements. The results found here show that more weight should be given to the mass fraction of arsenic and nickel to account for the stronger coloring effect compared to antimony. The distinct effects of high levels of arsenic and nickel (but also antimony) can be seen in several of the Sennwald-Salez axes as gray-bluish in appearance even in their patinated state (Figure 10). 


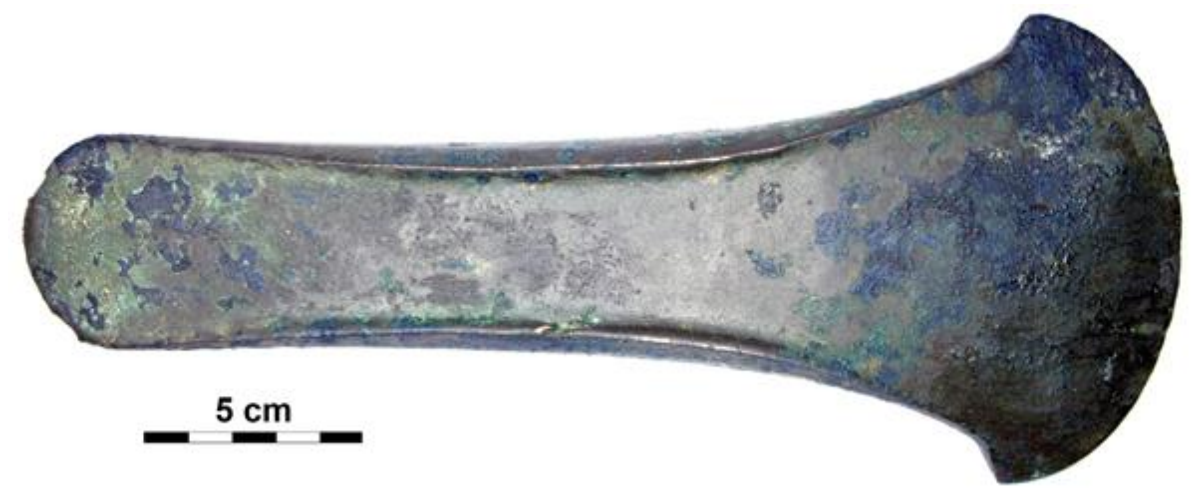

Figure 10 - Early Bronze Age axe from the Sennwald-Salez hoard, Canton St. Gallen, Switzerland. The axe contains $2.9 \mathrm{wt.} \%$ arsenic, $8.9 \mathrm{wt} . \%$ antimony and 4.9 wt.\% nickel (Photograph: M. Kuijpers, (C) Institut für Ur-und Frühgeschichte der Universität Wien).

Metal types III, IV, and VI (cf. Table 2) are all tin bronzes and need to be discussed in regard to the $\mathrm{CuSn}$ color measurements. However, a comparison must first be made to a previous attempt to measure the color of this alloy (Berger 2012; Fang and McDonnell 2011). Though there are slight differences in the exact numerical values, especially for $b^{*}$, the trends observed by these authors are largely comparable. A reduction of redness ( $\left.\mathrm{a}^{*}\right)$ is reported with the addition of tin up to c. $13 \mathrm{wt} . \%$ (Fang and McDonnell 2011 report 15 wt.\%). Above 15 wt.\% yellowness (b*) was also reduced, which gives the silvery appearance of high-tin bronzes (Fang and McDonnell 2011, 54). What these authors seem to have missed in their interpretation of the results is the increase in yellow (b*) of CuSn alloys in the range of 1-15 wt.\% tin. Pure copper has a value of $15.7\left(b^{*}\right)$ which increases to $20.7\left(b^{*}\right)$ in a $\mathrm{CuSn}$ alloy with $11 \mathrm{wt} . \%$ tin. The golden hue of these bronzes is thus not only an effect of reducing the redness (Fang and McDonnell 2011, 59), but also an increase of yellowness. On the basis of color the two categories of tin bronzes (metal type III and IV) can be confirmed, though from the perspective of color only the threshold between them should be in the range of 13-15 wt.\% instead of the suggested 12.

We realize that to move from quantitate color measurement to qualitative categories for metal types is tentative. However, it is these perceptive categories that are of interest to archaeologists in order to explore prehistoric metalworking. With re-melting, for instance, alloying to a specific outcome is difficult and entirely dependent upon the metalworkers' skill to adequately recognize varying copper compositions of the 'raw' (scrap) material that is being re-melted (cf. Hiorns 1912, 215). This happens at the expense of control over composition and is instead a matter of approximation. This is why we need the perceptive categories. They are broad categories that are scientifically less precise, but meaningful and relevant to metalworkers. As these categories can be substantiated through scientific measurements they are a helpful analytical tool through which scientific techniques can be integrated in archaeological interpretation (Pollard and Bray 2007).

\section{Conclusion}

The color characteristics of different copper alloys, such as $\mathrm{CuAs}, \mathrm{CuSn}, \mathrm{CuSb}$, and $\mathrm{CuNi}$ were evaluated photometrically using the CIELAB color system. This enabled us to document color differences in metal objects made of different copper alloys. The differences in color of the alloys studied were visualized and compared, clearly showing the warm-golden color of tin bronze, and the more silvery colors of the other alloys. This may give further indication of prehistoric metal production preferences, and if the alloys selected for the production of an object may have been chosen due to its color difference in comparison to the base copper metal. To address these matters we proposed to work with perceptive categories and tentatively proposed six different metal types that would have been recognizable and perceptibly different from a craftsperson's perspective. Further analyses of the color of ternary and quarternary copper alloys common in the archaeological record, 
such as $\mathrm{CuAsSn}, \mathrm{CuSnPb}, \mathrm{CuAsSb}$ or $\mathrm{CuAsSbNi}$ (cf. Figure 9), would help to develop this method further, and complete the discourse on colors of copper-based prehistoric objects.

\section{Acknowledgements}

The authors would like to acknowledge the financial support provided by the European Union's Horizon 2020 research and innovation program under the Marie Skłodowska-Curie Actions (grant agreement no. 656244); the Innovational Research Incentives Scheme (VICI) 'Economies of Destruction' of the Netherlands Organization for scientific Research; and the Deutsche Forschungsgemeinschaft for funding the research group FOR 550. The photometric analyses were carried out at the IRAMAT, University of Bordeaux.

\section{References}

1. Agricola, G. 1950. De Re Metallica. Dover Publications: New York.

2. Agricola, G. 1955. De Natura Fossilium (Textbook of Mineralogy), The Geological Society of America special paper. Geological Society of America.

3. Berger, D. 2012. Bronzezeitliche Färbetechniken an Metallobjekten nördlich der Alpen: Eine archäometallurgische Studie zur prähistorischen Anwendung von Tauschierung und Patinierung anhand von Artefakten und Experimenten. Forschungsberichte des Landesmuseums für Vorgeschichte Halle 2. Landesmuseum für Vorgeschichte Halle: Halle a. d. Saale.

4. Biringuccio, V. 1990. The Pirotechnia of Vannoccio Biringuccio. The Classic SixteenthCentury Treatise on Metals and Metallurgy. Dover Publications: New York.

5. Boivin, N. 2004. Mind over Matter? Collapsing the Mind-Matter Dichotomy in Material Culture Studies, in: DeMarrais, E., Gosden, C., Renfrew, C. (eds.), Rethinking Materiality; the Engagement of Mind with the Material World, McDonald Institute Monographs. McDonald Institute for Archaeological Research: Cambridge, 63-72.

6. Bray, P. 2012. Before $\mathrm{Cu}$ became copper: tracing the recognition and invention of metalleity in Britain and Ireland during the third millennium BC., in: Allen, M.J. - Gardiner, J. Sheridan, A. (eds.). Is There a British Chalcolithic? People, Place and Polity in the later Third Millennium. Prehistoric Society Research Paper 4, Prehistoric Society: London.

7. Budden, S. - Sofaer, J. R. 2009. Non-Discursive Knowledge and the Construction of Identity. Potters, Potting and Performance at the Bronze Age Tell of Százhalombatta, Hungary. Archaeological Review from Cambridge 19(2), 203-220.

8. Chapman, J. 2007. The elaboration of an aesthetic of brilliance and color in the climax Copper Age, in: Lang, F. - Reinholdt, C. - Weilhartner, J. (eds.). Stephanos Aristeios: Archäologische Forschungen zwischen Nil und Istros. Festschrift für Stefan Hiller zum 65. Geburtstag. Phoibos: Vienna, 65-74.

9. Chase, W. T. 1994. Chinese Bronzes: Casting, Finishing, Patination, and Corrosion. In: Scott, D. A. - Podany, J. - Considine B.B. (eds.). Ancient \& historic metals: conservation and scientific research. Proceedings of a symposium organized by the J. Paul Getty Museum and the Getty Conservation Institute, November 1991. Getty Conservation Institute: Marina del Rey, CA, 85-118.

10. Cretu, C. - Van der Lingen, E. 2000. Colored Gold Alloys. Gold Bulletin 32(4), 115-126.

11. Dobres, M.A. 2000. Technology and Social Agency: Outlining a Practice Framework for Archaeology. Oxford: Blackwell Publishers.

12. Dobres, M.A. 2010. Archaeologies of technology. Cambridge Journal of Economics 34, 103-114. doi:10.1093/cje/bep014

13. Fang, J.-L. - McDonnell, G. 2011. The color of copper alloys. Historical Metallurgy 45, $52-$ 61.

14. Germer, T. A. - Zwinkels, J. C. - Tsai, Benjamin K. 2014. Spectrophotometry: Accurate measurement of optical properties of materials. Experimental methods in the physical sciences 46 , Burlington. 
15. Gescheider, G.A. 1997. Psychophysics: The Fundamentals, 3rd ed. Lawrence Erlbaum Associates: London.

16. Gibson, J.J. 1979. The ecological approach to visual perception. Houghton Mifflin: Boston.

17. Guettier, A. 1872. A practical guide for the manufacture of metallic alloys: comprising their chemical and physical properties, with their preparation, composition, and uses. Henry Carey Baird, Industrial publisher: Philadelphia.

18. Hansen, S. 2013. Innovative Metals: Copper, Gold and Silver in the Black Sea Region and the Carpathian Basin During the 5th and 4th Millennium BC. In: Burmeister, S. - Hansen, S. Kunst, M. - Müller-Scheeßel, N. M. (eds.). Metal Matters. Innovative Technologies and Social Change in Prehistory and Antiquity. Marie Leidorf: Rahden/Westf ,137-170.

19. Hiorns, A.H. 1912. Mixed Metals and Metallic Alloys. Macmillan and co.: London.

20. Hosler, D. 1994. The Sounds and Colors of Power: The Sacred Metallurgical Technology of Ancient West Mexico. MIT Press: Cambridge, Mass.

21. Hosler, D. 1995. Sound, Color and Meaning in the Metallurgy of Ancient West Mexico. World Archaeology 27, 100-115.

22. Ingold, T. 2011. Being alive: essays on movement, knowledge and description. London: Routledge.

23. Johnston-Feller, R. 2001. Color science in the Examination of Museum Objects. The Getty Conservation Institute: Los Angeles.

24. Jones, A. - MacGregor, G. 2002. Coloring the Past: the significance of color in archaeological research. Berg: Oxford/New York.

25. Jones, A. 2004. Archaeometry and materiality: materials-based analysis in theory and practice. Archaeometry 46, 327-338. doi:10.1111/j.1475-4754.2004.00161.x

26. Juleff, G. - Bray, L. 2007. Minerals, Metal, Colors and Landscape: Exmoor's Roman Lode in the Early Bronze Age. Cambridge Archaeological Journal 17, 285-296. doi:10.1017/S0959774307000376

27. Kienlin, T. L. 2008. Frühes Metall im Nordalpinen Raum: Eine Untersuchung zu technologischen und kognitiven Aspekten früher Metallurgie anhand der Gefüge frühbronzezeitlicher Beile. Rudolf Habelt, Bonn.

28. Kienlin, T. L. 2010. Traditions and Transformations: approaches to Eneolithic (Copper age) and Bronze Age metalworking and society in eastern Central Europe and the Carpathian basin, BAR International Series 2184. Archaeopress: Oxford.

29. Kim, C. W. - Kim, H. G. - Suk, H. G. 2006. A Study on the Composition Determination of $\mathrm{Cu}$ Alloys by Image Processing Technology. Solid State Phenomena 116-117, 795-798. doi:10.4028/www.scientific.net/SSP.116-117.795

30. Killick, D. 2004. Social Constructionist Approaches to the Study of Technology. World Archaeology 36, 571-578.

31. Knappett, C. 2004. The Affordances of Things: a Post-Gibsonian Perspective on the Relationality of Mind and Matter. In: DeMarrais, E., Gosden, C., Renfrew, C. (eds.), Rethinking materiality: the engagement of mind with the material world. McDonald Institute Monographs. McDonald Institute for Archaeological Research: Cambridge, 43-51.

32. Konica Minolta, 2014, Spectrophotometer CM-2600d/2500d: Instruction manual.

33. Kuijpers, M.H.G. 2013. The sound of fire, taste of copper, feel of bronze, and colors of the cast: sensory aspects of metalworking technology, in: Sørensen, M.-L. S., Rebay-Salisbury, K. (eds.), Embodied Knowledge: Historical Perspectives on Belief and Technology. Oxbow Books: Oxford, 137-150.

34. Kuijpers, M.H.G. 2014. Early Bronze Age metalworking craftsmanship. An inquiry into metalworking skill and craft based on axes in the North-Alpine region. Unpublished $\mathrm{PhD}$ thesis, University of Cambridge.

35. Kuijpers, M.H.G. in press. An archaeology of skill. An enquiry into metalworking skill and material specialization based on Late Copper Age and Early Bronze Age axes from Central Europe. Routledge: London.

36. Lee, H. C. 2005. Introduction to color imaging science. Cambridge University Press: Cambridge. 
37. Lehoërff, A. 2007. L'Artisanat du Bronze en Italie Centrale (1200-725 avant notre ère). Le metal des dépôts volontaires. Bibliothèque des Écoles Françaises d'Athènes et de Rome 335. École Française de Rome: Rome.

38. Leusch, V. - Armbruster, B. - Pernicka, E. - Slavčev, V. 2015. On the Invention of Gold Metallurgy: The Gold Objects from the Varna I Cemetery (Bulgaria)-Technological Consequence and Inventive Creativity. Cambridge Archaeological Journal 25, 353-376. doi:10.1017/S0959774314001140

39. Malafouris, L. 2004. The Cognitive Basis of Material Engagement: Where Brain, Body and Culture Conflate, in: DeMarrais, E., Gosden, C., Renfrew, C. (eds.), Rethinking Materiality: the Engagement of Mind with the Material World. McDonald Institute Monographs. McDonald Institute for Archaeological Research: Cambridge, 53-62.

40. Malafouris, L. 2013. How Things Shape the Mind: A Theory of Material Engagement. EBL-Schweitzer. The MIT Press, Cambridge, Massachusetts.

41. Merkl, M. B. 2010. Bell Beaker Metallurgy and the Emergence of Fahlore-copper Use in Central Europe. Interdisciplinaria Archaeologica: Natural sciences in Archaeology 1(1-2), 19-27.

42. Mödlinger, M. - Sabatini, B. 2016. A Re-evaluation of inverse segregation in prehistoric $\mathrm{Cu}$ As objects. Journal of Archaeological Science 74, 60-74. DOI 10.1016/j.jas.2016.08.005.

43. Nassau, K., 2001. Color for science, art and technology. Azimuth 1. Elsevier, Amsterdam.

44. Ottaway, B. S. 2001. Innovation, production and specialisation in early prehistoric copper metallurgy. European Journal of Archaeology 4, 87-112.

45. Pearce, M. 2007. Bright Blades and Red Metal. Essays on North Italian Prehistoric Metalwork. Accordia specialist studies on Italy 14. Accordia Research Institute: London.

46. Pollard, A.M. - Bray, P. A Bicycle Made for Two? The Integration of Scientific Techniques into Archaeological Interpretation. Annual Review of Anthropology 36 (1), 245-259.

47. Radivojević, M. - Rehren, Th. - Pernicka, E. - Šljivar, D. - Brauns, M. - Borić, D. 2010. On the origins of extractive metallurgy: new evidence from Europe. Journal of Archaeological Science 37, 2775-2787.

48. Radivojević, M. 2015. Invention of metallurgy in western Eurasia: a look through the microscope lens. Cambridge Archaeological Journal 25 (1), 321-338.

49. Renfrew, C. 2004. Towards a theory of material engagement, in: De Marrais, E. - Gosden, C. - Renfrew, C. (eds.), Rethinking Materiality: the Engagement of Mind with the Material World. McDonald Institute Monographs. McDonald Institute for Archaeological Research: Cambridge, 23-31.

50. Saeger, K. E. - Rodies, J. 1977. The color of gold and its alloys: The mechanism of variation in optical properties. Gold Bulletin 10(1), 10-14.

51. Smith, C.S. 1975. Metallurgy as a human experience. Metallurgical Transactions A 6(4), 603-623. doi:10.1007/BF02672281

52. Stevens, F. 2008. Elemental interplay: the production, circulation and deposition of Bronze Age metalwork in Britain and Ireland. World Archaeology 40, 238-252.

53. Teghtsoonian, M. 2001. Sensation and Perception: Direct Scaling, in: Smelser, N.J., Baltes, P.B. (eds.). International Encyclopedia of the Social and Behavioral Sciences. Elsevier, Amsterdam, 13902-13905.

54. Thornton, C.P. 2009. Archaeometallurgy: Evidence of a Paradigm Shift?, in: Roberts, B.W. Kienlin, T.L. (eds.). Metals and Societies. Studies in Honour of Barbara S. Ottaway, Universitätsforschungen Zur Prähistorischen Archäologie. Habelt: Bonn, 25-33.

55. Untracht, O., 1968. Metal techniques for craftsmen: a basic manual for craftsmen on the methods of forming and decorating metals. Hale: London.

56. Villegas, M. A. U. - Martinón-Torres, M.-T. 2012. Composition, color and context in Muisca votive metalwork (Colombia, AD 600-1800). Antiquity 86, 772-791.

57. Yonehara, M. - Matsui, T. - Kihara, K. - Isono, H. - Kijima, A. - Sugibayashi, T. 2004. Experimental Relationships between Surface Roughness, Glossiness and Color of Chromatic Colored Metals. Materials Transactions 45(4), 1027-1032. 


\section{Figure and table captions}

Figure 1 - Bronze Age dagger from Koban, Republic of North Ossetia-Alania, Russia. The color of the hilt was silverish while the blade had a warm, golden-like color. The hilt contains about $9.8 \mathrm{wt} . \%$ arsenic and no tin, while the blade contains $10.1 \mathrm{wt} . \%$ tin, and no arsenic. Today, the dagger is very much corroded, so the original colors of the metals are no longer visible (Photograph: M. Mödlinger, (C) Naturhistorisches Museum Wien).

Figure 2 - Schematic drawing of the sample illumination during the color measurements with the MINOLTA CM-2600D spectrophotometer using an integration sphere. Due to the sequential application of two different light sources (1 and 2), quasi-simultaneous measurements of the diffuse and specular components of the reflectance are possible (drawing: after Konica Minolta 2014, E-116)

Figure 3 - The $\mathrm{L}^{*}, \mathrm{a}^{*}, \mathrm{~b}^{*}$ three-dimensional coordinate system. $\mathrm{L}^{*}$ ranges from $0 \%$ (black) to $100 \%$ (white), $a^{*}$ from -100 (green) over 0 (grey) to 100 (red), while $b^{*}$ ranges from -100 (blue) over 0 (grey) to 100 (yellow).

Figure 4 - Two-dimensional chromaticity diagram of the $\mathrm{L}^{*} \mathrm{a}^{*} \mathrm{~b}^{*}$ color space with a view to the $\mathrm{a}^{*} \mathrm{~b}^{*}$ plane with constant $\mathrm{L}^{*} . \mathrm{C}^{*}$ and $\mathrm{h}$ can also be included in diagram (drawing: D. Berger)

Figure 5 - CIELAB SR coordinates with error bars (Standard deviation: $2 \sigma$ ) of samples polished with $1 \mu \mathrm{m}$ diamond paste of selected pure elements: copper, nickel, tin, and antimony (left). Spectra of the same elements (mean value of 7-10 spectra) (right).

Figure 6 - CIELAB coordinates (SR) with error bars (standard deviation: $2 \sigma$ ) of each copper alloy examined in this study.

Figure 7 - Spectral distribution curves of the same alloys as shown in Figure 6 with wavelength vs. total reflectance. For each alloy 7-10 measurements were taken and averaged.

Figure 8 - Polynomic lines of the CIELAB coordinates for each alloy (see also Figure 6), including the estimated coordinates for the hilt and blade of the dagger (Figure 1) according to the alloy composition of both hilt and blade.

Figure 9 - The effect of different alloy additives on copper shown as the dependence of chroma (a) and hue (b) from the amount of alloying element given in wt.\%. In c) chroma vs. hue of the different alloys is shown. Chroma given in \%.

Figure 10 - Early Bronze Age axe from the Sennwald-Salez hoard, Canton St. Gallen, Switzerland. The axe contains 2.9 wt.\% arsenic, 8.9 wt.\% antimony and 4.9 wt.\% nickel (Photograph: M. Kuijpers, (c) Institut für Ur- und Frühgeschichte der Universität Wien).

Table 1 - Alloy composition and color data (SR values) of the metal samples. The composition of the alloys is given in wt.\%. Alloys with * are as-cast and may contain up to 0.5 total wt. $\%$ of $\mathrm{Si}, \mathrm{Cl}, \mathrm{Ca}$, $\mathrm{P}, \mathrm{S}, \mathrm{Fe}$, and $\mathrm{K}$. All other alloys were made with electrolytic copper and were cold-rolled. The composition of the alloys with * were studied by WDXRF, and the chemical composition of all other alloys by EDXRF. The CIELAB coordinates are shown in Figures $4-8$ and are the average of 7-10 spectra.

Table 2 - Perceptive categories of different CuSn metal types as thought relevant and perceivable to metalworkers. These metal types are based on interviews with contemporary craftspeople, historical sources, and experimental archaeology (from Kuijpers 2014; in press). 